\title{
PENGGUNAAN EDUKASI BOOKLET TERHADAP SIKAP REMAJA PADA PERILAKU MEROKOK
}

\author{
Gani Apriningtyas Budiyati' ${ }^{1}$, Pipin Nurhayati ${ }^{2}$ \\ ${ }^{1}$ Jurusan Keperawatan,STIKes Surya Global \\ Email: gani.apriningtyas@gmail.com \\ 2 Jurusan Keperawatan, STIKes Surya Global \\ Email: pipin.nurhayati@gmail.com
}

Masuk: 28-08-2020, revisi: 27-10-2021, diterima untuk diterbitkan: 29-10-2021

\begin{abstract}
ABSTRAK
Merokok pada usia remaja semakin meningkat. Penanggulangan perilaku merokok pada remaja diperlukan, yang salah satu caranya adalah dengan memprediksi perilaku sesuai dengan Theory of Planned Behavior (TPB). Dalam TPB ini dijelaskan bahwa sikap individu merupakan prediktor yang dapat mempengaruhi keputusan individu untuk melakukan perilaku. Oleh karena itu, diperlukan adanya intervensi yang dapat digunakan untuk mempengaruhi sikap individu tentang perilaku merokok agar dapat menurunkan perilaku merokok khususnya pada remaja. Desain penelitian ini adalah one group pre test-post test. Analisa univariabel digunakan dengan melakukan perhitungan frekuensi untuk mengetahui karakteristik responden yang meliputi jenis kelamin, usia, kelas, status merokok dan usia pertama kali mencoba merokok. Analisa bivariabel digunakan untuk mengetahui perbedaan sikap, sebelum dan setelah diberi penyuluhan menggunakan uji Wilcoxon. Hasil penelitian menunjukkan mayoritas responden dalam penelitian ini yaitu perempuan $(53,48 \%)$, mayoritas memiliki usia $\geq 17$ tahun yaitu sebesar $62,79 \%$., mayoritas terdiri dari remaja kelas XI yaitu 65,12\%. Pada status merokok remaja diketahui bahwa mayoritas saat ini remaja tidak merokok yaitu sebesar $67,4 \%$. Pada remaja juga diketahui bahwa mereka pernah mencoba merokok untuk pertama kali yaitu usia $\geq 13$ tahun. Pada uji bivariabel terdapat perbedaan yang signifikan pada sikap remaja terhadap perilaku merokok antara sebelum dan setelah dilakukan penyuluhan dengan nilai $\mathrm{p}$ sebesar $0,001(\mathrm{p}<0,05)$. Kesimpulan penelitian ini yaitu terdapat pengaruh edukasi dengan booklet terhadap sikap remaja pada perilaku merokok.
\end{abstract}

Kata Kunci: booklet; edukasi;remaja;sikap; merokok

\begin{abstract}
Smoking in adolescence is increasing. Prevention of smoking behavior in adolescents is needed, one of which is to predict behavior according to the Theory of Planned Behavior (TPB). In this TPB, it is explained that individual attitudes are predictors that can influence an individual's decision to perform a behavior. Therefore, it is necessary to have an intervention that can be used to influence individual attitudes about smoking behavior in order to reduce smoking behavior, especially in adolescents. The design of this research is one group pre test-post test. Univariable analysis was used to calculate the frequency to determine the characteristics of the respondents which included gender, age, class, smoking status and age for the first time trying smoking. Bivariable analysis was used to determine differences in attitudes, before and after being given counseling using the Wilcoxon test. The results showed that the majority of respondents in this study were women (53.48\%), the majority had an age of 17 years, which was $62.79 \%$. The majority consisted of teenagers in class XI, which was $65.12 \%$. In the smoking status of adolescents, it is known that the majority of adolescents do not smoke, which is 67.4\%. In adolescents, it was also known that they had tried smoking for the first time, namely at the age of 13 years. In the bivariable test, there was a significant difference in adolescent attitudes towards smoking behavior between before and after counseling with a $p$ value of 0.001 ( $p<0.05$ ). The conclusion of this study is that there is an effect of education with booklets on adolescent attitudes towards smoking behavior.
\end{abstract}

Keywords: booklet;education;adolescent;attitude,smoking 


\section{PENDAHULUAN}

\section{Latar Belakang}

Global Adult Tobacco Survey (GATS) (2012) menjelaskan bahwa remaja telah memulai untuk mencoba merokok sebelum mereka berusia 20 tahun. Selain itu, remaja merupakan populasi yang dikhawatirkan sulit berhenti merokok dibandingkan dengan populasi usia yang lebih tua (Wijayanti, Dewi \& Rifqatussa'adah, 2017). Penelitian Ladapo et.al (2014) menunjukkan bahwa anak berusia 11 tahun telah melakukan perilaku merokok. Anak anak pada tingkat kelas 5 bahkan memiliki faktor risiko yang sama untuk merokok dibandingkan dengan remaja/anak-anak yang lebih tua dari itu. Dalam penelitian Astuti (2012) ditemukan bahwa remaja berusia 14 tahun sudah menjadi perokok harian. Berdasarkan data terkait dengan perilaku merokok pada remaja tersebut, diperlukan adanya upaya untuk menanggulangi perilaku merokok pada remaja.

Leeuw, Valois, Ajzen, \& Schmidt (2015) menjelaskan bahwa model Theory of Planned Behavior (TPB) dapat memprediksi perilaku dengan mendeskripsikan sikap, norma subjektif, niat dan perilaku yang terprediksi pada perilaku remaja. Ajzen (2012) menjelaskan bahwa Theory of Planned Behavior mampu memprediksi perilaku dengan beberapa domain yaitu sikap, norma subjektif, control perilaku yang dipersepsikan, dan niat individu. Leeuw, Valois, Ajzen, \& Schmidt (2015) menjelaskan bahwa perilaku remaja dapat dipengaruhi oleh perilaku lingkungan. Perilaku lingkungan kemudian membentuk serta memengaruhi sikap, norma subjektif remaja, perilaku dan niat dalam melakukan sesuatu. Dalam penelitian lain dijelaskan bahwa faktor yang memengaruhi remaja merokok yaitu jenis kelamin, usia, pengalaman, sikap dan pengetahuan (Wijayanti, Dewi \& Rifqatussa'adah, 2017).

Dharmastuti (2017) menyatakan bahwa pendidikan kesehatan dapat menjadi salah satu usaha untuk menghentikan kebiasaan merokok. Adanya pemberian edukasi tentang bahaya merokok berpengaruh terhadap pengetahuan dan sikap remaja. Pendidikan kesehatan dengan media booklet mampu meningkatkan pengetahuan bagi remaja dan mengubah sikap remaja ke arah yang lebih positif. Natalansyah \& Nyamin (2020) dalam penelitiannya menyebutkan bahwa pendidikan kesehatan dengan media booklet mampu meningkatkan pengetahuan dan sikap individu. Hal ini terlihat dari pengukuran nilai pengetahuan dan sikap remaja yang semakin meningkat setelah diberikan edukasi booklet. Hal yang penting untuk menjadi perhatian adalah bahwa edukasi menggunakan booklet ini dapat meningkatkan kesadaran masyarakat baik di pelayanan kesehatan maupun komunitas akan pentingnya perilaku hidup sehat. Adanya peningkatan perilaku hidup sehat pada responden setelah mendapatkan edukasi booklet juga dapat menjadi gambaran bagi para tenaga kesehatan untuk semakin meningkatkan pengetahuan dan kesadaran masyarakat menggunakan media tersebut (Ijone,2017). Selain itu, menurut Dharmastuti (2017) booklet terbukti lebih efektif untuk digunakan sebagai media pemberian informasi kesehatan dibandingkan dengan poster.

\section{Rumusan Masalah}

Dari uraian di atas penulis tertarik untuk merumuskan masalah "Apakah terdapat pengaruh edukasi dengan booklet terhadap sikap remaja pada perilaku merokok?”

\section{METODE PENELITIAN}

Desain penelitian ini adalah one group pre test-post test (Notoatmodjo, 2010). Penelitian ini dilakukan pada bulan Juli 2020 di SMA TM kota Yogyakarta. Populasi pada penelitian ini adalah remaja yang merupakan siswa kelas X,XI SMA TM Kota Yogyakarta. Jumlah siswa kelas $\mathrm{X}$ yaitu 15 orang dan kelas XI yaitu 29 orang. Total populasi yaitu 45 orang. Sampel penelitian ini menggunakan total sampling. 
Variabel independent dalam penelitian ini yaitu edukasi bahaya merokok pada remaja dengan menggunakan media booklet. Variabel dependent dalam penelitian ini adalah sikap remaja terhadap perilaku merokok. Instrumen penelitian berupa kuesioner karakteristik responden, kuesioner untuk mengukur sikap berdasarkan adopsi dari Budiyati (2018). Hasil uji validitas kuesioner dalam penelitian ini menunjukkan bahwa pada kuesioner sikap dinyatakan valid dengan nilai $r$ 0,449-0,566. Kuesioner dalam penelitian ini telah digunakan dalam penelitian Budiyati (2018) dan dilakukan uji reliabilitas. Hasil uji reliabilitas untuk kuesioner sikap sebesar 0,732 .

Analisa univariabel digunakan dengan melakukan perhitungan frekuensi untuk mengetahui karakteristik responden yang meliputi jenis kelamin, usia, kelas, status merokok dan usia pertama kali mencoba merokok. Analisa bivariabel digunakan untuk mengetahui perbedaan sikap, sebelum dan setelah diberi penyuluhan. Untuk analisa data tersebut peneliti menggunakan uji Wilcoxon. Sebelum dilakukan uji beda, terlebih dahulu dilakukan uji normalitas data.

\section{HASIL DAN PEMBAHASAN}

\section{a. Hasil penelitian}

Berdasarkan tabel 1 diketahui bahwa mayoritas responden dalam penelitian ini yaitu perempuan $(53,48 \%)$. Sedangkan untuk usia responden, mayoritas memiliki usia $\geq 17$ tahun yaitu sebesar $62,79 \%$. Pada karakteristik responden berupa kelas, menunjukkan bahwa mayoritas terdiri dari remaja kelas XI yaitu $65,12 \%$. Pada status merokok remaja diketahui bahwa mayoritas saat ini remaja tidak merokok yaitu sebesar $67,4 \%$. Pada remaja juga diketahui bahwa mereka pernah mencoba merokok untuk pertama kali yaitu usia $\geq 13$ tahun. Pada data karakteristik responden juga diketahui bahwa terdapat remaja yang mencoba rokok untuk pertama kalinya pada usia <13 tahun.

Tabel 1. Karakteristik responden

\begin{tabular}{lcc}
\hline Variabel & Frekuensi (n) & Persentase (\%) \\
\hline Jenis Kelamin & & \\
\hline Laki-laki & 20 & $46,51 \%$ \\
Perempuan & 23 & $53,48 \%$ \\
\hline Jumlah & 43 & $100 \%$ \\
\hline Usia & & $37,2 \%$ \\
\hline$<17$ tahun & 16 & $62,79 \%$ \\
\hline$\geq 17$ tahun & 27 & \\
\hline Kelas & & $34,88 \%$ \\
\hline$X$ & 15 & $65,12 \%$ \\
\hline XI & 29 & \\
\hline $\begin{array}{l}\text { Status } \\
\text { merokok }\end{array}$ & & $67,4 \%$ \\
\hline Tidak merokok & 31 & $32,55 \%$ \\
\hline Merokok & 14 & \\
\hline $\begin{array}{l}\text { Usia pertama } \\
\text { mencoba }\end{array}$ & & \\
rokok & & $28,6 \%$ \\
\hline$<13$ tahun & 4 & $71,4 \%$ \\
\hline$\geq 13$ tahun & 10 & \\
\hline
\end{tabular}


Pada penelitian ini juga dideskripsikan terkait sikap siswa sebelum dan setelah dilakukan edukasi menggunakan booklet. Tabel 2 menjelaskan tentang sikap siswa sebelum dilakukan edukasi menggunakan booklet pada remaja. Hasil menunjukkan bahwa sikap remaja yang tidak mendukung perilaku merokok sebanyak 31 orang $(72,1 \%)$ sedangkan remaja yang memiliki sikap mendukung perilaku merokok sebanyak 12 orang $(27,9 \%)$. Hasil ini jika dibandingkan dengan data sikap remaja terhadap merokok sesudah pemberian edukasi booklet pada tabel 3 menunjukkan bahwa terdapat kenaikan jumlah remaja yang memiliki sikap tidak mendukung terhadap perilaku merokok yaitu sebesar $81,4 \%$. Sedangkan jumlah remaja yang masih memiliki sikap mendukung perilaku merokok telah mengalami penurunan menjadi 18,6\%. Dari hasil ini dapat diketahui bahwa terdapat peningkatan sikap remaja untuk tidak mendukung pada perilaku merokok.

Tabel 2. Analisis univaribel sikap sebelum edukasi dengan booklet Sumber tabel: Data primer 2020

\begin{tabular}{ccc}
\hline Sikap & Frekuensi (n) & Persentase (\%) \\
\hline Tidak mendukung & 31 & $72,1 \%$ \\
Mendukung & 12 & $27,9 \%$ \\
\hline Total & 43 & $100 \%$ \\
\hline
\end{tabular}

Tabel 3. Analisis univariabel sikap setelah edukasi dengan booklet Sumber tabel: Data primer 2020

\begin{tabular}{ccc}
\hline Sikap & Frekuensi (n) & Persentase (\%) \\
\hline Tidak mendukung & 35 & $81,4 \%$ \\
Mendukung & 8 & $18,6 \%$ \\
\hline Total & 43 & $100 \%$ \\
\hline
\end{tabular}

Uji bivariabel dalam penelitian ini menggunakan uji Wilcoxon untuk mengetahui perbedaan sikap sebelum dan setelah dilakukan edukasi menggunakan booklet. Dari tabel 4 didapatkan hasil bahwa terdapat perbedaan yang signifikan pada sikap remaja terhadap perilaku merokok antara sebelum dan setelah dilakukan penyuluhan dengan nilai $\mathrm{p}$ sebesar $0,001(\mathrm{p}<0,05)$.

\begin{tabular}{lc} 
Tabel 4. Hasil Uji Tes Wilcoxon \\
\hline Asymp. Sig 2 tailed & 0,001 \\
\hline
\end{tabular}

\section{b. Pembahasan}

Penelitian Negoro (2016) menjelaskan bahwa remaja terpengaruh untuk melakukan perilaku merokok antara lain disebabkan karena adanya ajakan oleh teman. Remaja dalam hal melakukan perilaku merokok sangat terpengaruh pada lingkungan sosialnya. Perilaku remaja terkait dengan merokok ini salah satunya juga dipengaruhi adanya informasi dan pengetahuan dalam bentuk gambar. Gambar yang mencantumkan sesuatu yang tidak sesuai dengan perasaan remaja turut memengaruhi keyakinan dan sikap yang dimiliki. Adanya gambar dan informasi yang tidak baik terhadap merokok menjadi suatu tekanan psikologis yang secara terus menerus menjadi pendorong pada perubahan sikap dan memengaruhi perilaku.

Sikap merupakan penilaian terhadap suatu hal. Sehingga sikap remaja terhadap rokok berarti penilaian remaja pada perilaku merokok. Sikap ini merupakan salah satu indikator terhadap perilaku (Leeuw, Valois, Ajzen, \& Schmidt, 2015). Dalam penelitian Wijayanti, Dewi \& Rifqatussa'adah (2017) menunjukkan bahwa terdapat hubungan antara sikap dengan perilaku merokok pada remaj. Selain itu sikap sejalan dengan perilaku individu. Adanya peningkatan ilmu pengetahuan dengan media booklet dapat menjadi transformasi dari sikap menyetujui 
perilaku merokok ke sikap tidak setuju terhadap perilaku merokok. Sikap menjadi salah satu indikator dalam perilaku. Sehingga adanya perubahan sikap individu dengan media booklet ini diharapkan dapat meningkatkan kesadaran terhadap perilaku kesehatan (Pardosi, 2019).

Dari penelitian didapatkan hasil bahwa terdapat perubahan sikap tidak mendukung terhadap perilaku merokok pada remaja. Selain itu dari hasil uji bivariabel didapatkan data bahwa terdapat perbedaan yang signifikan antara sebelum dan setelah dilakukan edukasi menggunakan booklet. Hal tersebut menunjukkan bahwa booklet memiliki pengaruh terhadap sikap remaja pada perilaku merokok. Hal ini sejalan dengan hasil penelitian Pardosi (2019) yang menyatakan bahwa edukasi dengan menggunakan booklet terbukti efektif untuk meningkatkan pengetahuan dan sikap remaja. Dari penelitian ini juga menunjukkan bahwa dengan menggunakan media booklet remaja dapat meningkatkan pengetahuan dan sikap terhadap perilaku yang menunjang kesehatannya dengan meningkatkan perilaku membaca. Hasil yang serupa ditunjukkan pada penelitian Vahedian, Sadeghi, Farhadlu, Nazeri, Dehghan \& Barati (2014) bahwa remaja yang diberikan penyuluhan baik menggunakan media pembelajaran di kelas maupun booklet menunjukkan hasil yang sama signifikan pada peningkatan aspek pengetahuan, sikap maupun perilaku remaja terkait peningkatan perilaku kesehatan. Hal ini juga didukung Kulsum, Rouf \& Irwansyah (2019) yang menjelaskan bahwa penyuluhan tentang kesehatan juga dapat meningkatkan pengetahuan dan perilaku lebih sehat pada anak-anak.

Manfaat lain dari booklet selain dapat meningkatkan pengetahuan yang diikuti peningkatan sikap remaja. Booklet dapat meningkatkan kesehatan psikologis para remaja. Faktor yang menyebabkan antara lain adalah pengetahuan remaja tentang masalah yang sedang dialaminya dan kepahaman remaja terhadap batasan yang ada pada dirinya dengan membaca informasi dari booklet (Schiller et.al., 2014). Adanya booklet yang dibagikan pada masyarakat juga mampu mengurangi permintaan terhadap layanan terutama untuk penyakit minor. Hal ini disebabkan karena adanya peningkatan pengetahuan pada masyarakat (Heaney,Wyke, Wilson, Elton, Rutledge, 2001). Beberapa hal yang menyebabkan perubahan pengetahuan dan sikap pada remaja antara lain jika media menarik, bahasa yang sederhana, mudah dibawa, mudah disimpan (Sari et al., 2017).

\section{KESIMPULAN DAN SARAN}

Berdasarkan hasil penelitian, didapatkan hasil bahwa nilai p sebesar 0,001. Hasil tersebut menunjukkan bahwa terdapat pengaruh edukasi dengan menggunakan media booklet terhadap sikap remaja pada perilaku merokok. Dari hasil tersebut diharapkan agar pendidikan kesehatan untuk mengubah sikap remaja dari mendukung perilaku merokok menjadi tidak mendukung perilaku merokok dapat dilakukan dengan menggunakan media booklet. Saran untuk peneliti selanjutnya dapat menggunakan metode penelitian yang lebih advance untuk mengkaji lebih mendalam keefektifan media booklet terhadap sikap remaja pada perilaku merokok.

\section{REFERENSI}

Ajzen,I. (2012). The Theoy of Planned Behavior. In P.A.M. Lange, A. W. Krugalanski \& E.T. Higgins (Eds.). Handbook of Theories of Social Psychoogy,1, 438-459. London, UK: Sage

Astuti,K. (2012). "Gambaran Perilaku Merokok Pada Remaja di Kabupaten Bantul”. Insight,10 (1), 7787. 
Budiyati,G.A.(2018). Literasi Kesehatan Dan Perilaku Pada Remaja: Studi Potong Lintang Berbasis Theory Of Planned Behavior Tentang Sikap, Norma Subjektif, Perceived Behavioral Control Dan Intensi Perilaku Merokok. Tesis. Universitas Gadjah Mada.

Dharmastuti, S. P. dkk (2017) Pengaruh Pendidikan Kesehatan Tentang Bahaya Merokok Melalui Media Booklet Dan Poster Terhadap Pengetahuan Dan Sikap Siswa Smp N 2 Tasikmadu. Skripsi thesis, Universitas Muhammadiyah Surakarta.

GATS (Global Adult Survey): Indonesia Report 2011. (2012). Retrieved from: www.searo.who.int/tobacco/data/gats_indonesia_2011.pdf Riset Kesehatan Dasar RISKESDAS. (2013). Badan Penelitian dan Pengembangan Kesehatan Kementerian. Kesehatan RI Tahun 2013. Retrieved from: http://www.depkes.go.id/resources/download/general/Hasil\%20Riskesdas\%202013.

Global Youth Tobacco Survey Part 3. (2008). Retrieved from: https://www.cdc.gov/tobacco/global/gtss/tobacco_atlas/pdfs/part3.pdf

Heaney,D.,Wyke, S., Wilson, P., Elton,R., Rutledge,P. (2001). "Assessment of impact of information booklets on use of healthcare services: randomised controlled trial". BMJ, 322,1-5.

Ijone. (2017). A Study to Assess The Effectiveness of Information Booklet on Knowledge and Attitude of People regarding Organ Donation in Rural Area of Haryana. International Journal of Nursing Education, 9,4

Kulsum,Q.D., Rouf,S.A., \& Irwansyah,F.S. (2019). Edukasi Zat Aditif Melalui Demonstrasi Kimia Di Sdn Buangngariung Wado.Jurnal Pengabdian Masyarakat Al Khidmat,2 (2).

Ladapo,J.A., Elliot,M.N., Kanouse,D.E., Tortolero,S.R.,..., Schuster,M.A. (2014). "Tobacco Use and Smoking Intentions Among U.S. Fifth-Grade Students". Journal of Adolescent Health, 55, 445451. http://dx.doi.org/10.1016/j.jadohealth.2014.03.008.

Leeuw,A., Valois,P., Ajzen,I.,\& Schmidt,P. (2015). "Using the Theory of Planned Behavior to Idnetify Key Beliefs Underlying Pro-Environmental Behavior in High-School Students: Implications for Educational Interventions". Journal of Environmental Psychology,128-138. http://dx.doi.org/10.1016/j.jenvp.2015.03.005

Natalansyah, N., \& Nyamin, Y. (2020). Peran Booklet Terhadap Pengetahuan, Sikap, Perilaku JumantikPSN dan Keberadaan Jentik Di Panarung, Kota Palangkaraya. Jurnal Persatuan Perawat Nasional Indonesia (JPPNI), 4(3), 150-161.

Negoro,S.H. (2016). "Pembentukan Sikap Oleh Perokok Remaja Melalui Peringatan Bahaya Merokok Pada Kemasan Rokok". Jurnal Interaksi, 5 (2), 112-122.

Notoatmodjo (2010). Metodologi Penelitian Kesehatan. Jakarta: Rineka Cipta.

Pardosi,M. (2019). "The Effectiveness of Booklet of Anemia on The Behaviors of Adolescent Girls". Global Journal of Health Science, 11 (10). doi:10.5539/gjhs.v11n10p111

Sari,P., Rusmil,K., Kartasasmita,A.S., Farid, Rajab,TLE., Sunjaya,D.K., Judistiani,T.D. (2017). "Proceeding Book The 4th International Conference On Health Science. The Effectiveness Of Health Education Through Smartphone And Booklet On Knowledge And Attitude Of Adolesence Reproductive Health", 55.

Schiller,Y., Schulte-Ko "rne,G., Eberle-Sejari,R., Maier,B., Allgaier,A.K. (2014) .’Increasing knowledge about depressiom in adolescents: Effects of an information booklet". Yvonne Social Psychiatry Epidemiology (2014) 49:51-58.

Vahedian,M., Sadeghi, R., Farhadlu, R., Nazeri,A., Dehghan,A., Barati,M.H. (2014). "Effect of Educational Booklet and Lecture on Nutritional Behavior, Knowledge and Attitude on Third-Grade Male Gudance School Students". Journal of Community Health Research, 3(1),1-12.

Wijayanti,E., Dewi,C., Rifqatussa'adah. (2017). "Faktor-faktor yang Berhubungan Dengan Perilaku Merokok Pada Remaja Kampung Bojong Rawalele Jatimakmur Bekasi”. Global Medical and Health communication, 5 (3), 194-198. 